Research

\title{
Therapeutic efficacy of sulphadoxine-pyrimethamine and chloroquine for the treatment of uncomplicated malaria in pregnancy in Burkina Faso
}

\author{
Sheick Oumar Coulibaly*1,3, Désiré Nezien ${ }^{1}$, Salifou Traoré2 ${ }^{2}$ Bibiane Koné3 \\ and Pascal Magnussen 4
}

\begin{abstract}
Address: ${ }^{1}$ Laboratoire National de Santé Publique, 09 BP 24 Ouagadougou 09, Burkina Faso, ${ }^{2}$ Centre Medical Paul VI, 01 BP 2099 Ouagadougou 01, Burkina Faso, ${ }^{3}$ UFR Sciences de la Santé, Université de Ouagadougou, 03 B.P. 7021 Ouagadougou 03, Burkina Faso and ${ }^{4}$ DBL - Institute for Health Research and Development, Copenhagen, Jaegersborg Allé 1 D DK-2920 Charlottenlund, Denmark
\end{abstract}

Email: Sheick Oumar Coulibaly* - sheickoumar2@yahoo.fr; Désiré Nezien - neziendesire8@yahoo.fr; Salifou Traoré - traoresalifb@yahoo.fr; Bibiane Koné - bkone@caramail.com; Pascal Magnussen - pmagnussen@dblnet.dk

* Corresponding author

Published: 15 June 2006

Malaria Journal 2006, 5:49 doi:10.1 186/1475-2875-5-49

This article is available from: http://www.malariajournal.com/content/5///49

(c) 2006 Coulibaly et al; licensee BioMed Central Ltd.

This is an Open Access article distributed under the terms of the Creative Commons Attribution License (http://creativecommons.org/licenses/by/2.0), which permits unrestricted use, distribution, and reproduction in any medium, provided the original work is properly cited.
Received: 30 March 2006

Accepted: 15 June 2006

\begin{abstract}
Background: A reduction in the therapeutic efficacy of chloroquine (CQ) and sulphadoxinepyrimethamine (SP) has recently been observed in Burkina Faso. As these two drugs are used in pregnancy, their efficacy in pregnant women was studied to directly assess the level of drug resistance in this specific population, rather than to extrapolate results of studies conducted in children $<5$ years of age.

Methods: During the malaria transmission season of 2003 in Ouagadougou, the clinical efficacy of $\mathrm{SP}$ and $\mathrm{CQ}$, using the WHO 28-day protocol, was assessed in primigravidae and secundigravidae presenting with uncomplicated malaria.

Results: PCR-corrected results by day 28 showed that among 62 women treated with SP, eight (I2.9\%) experienced late parasitological failure, but no clinical failures. Among 60 women treated with CQ, the overall failure rate was $46.7 \%$ including $1.7 \%$ early treatment failures, $5 \%$ late clinical failures and $40 \%$ late parasitological failures. SP induced a haemoglobin gain of $0.3 \mathrm{~g} / \mathrm{dL}$ by day 14 and $0.9 \mathrm{~g} / \mathrm{dL}$ by day 28 . Treatment responses were independent of gravidity, gestational age and prior antenatal care visits.

Conclusion: While CQ should no longer be used, the efficacy of SP is still compatible with use for intermittent preventive treatment (IPT) in pregnancy. However, given the possible spread of resistance, the drug should be restricted in its use.
\end{abstract}

\section{Background}

Malaria remains one of the major infectious diseases threatening the health of pregnant women in Africa [1]. Pregnancy associated malaria affects birth outcome by causing maternal anaemia, stillbirths, abortion and low birth weight infants [2-9].

Case management of malaria in pregnancy should include effective and safe drugs to ensure maternal recovery and 
prevent adverse consequences for the foetus. When implementing new treatment and prevention policies, particular interest should be given to pregnant women as the number of antimalarial drugs safe to be used in pregnancy is limited.

It is only recently that Burkina Faso, where malaria is endemic but with marked seasonal transmission, has experienced increasing levels of resistance to chloroquine (CQ) and to some extent to sulphadoxine-pyrimethamine (SP) [10-14]. Historically, CQ has been used as the firstline drug for treatment of the general population, including pregnant women, and SP was used as second-line treatment. CQ was used for weekly chemoprophylaxis in pregnancy. A new malaria treatment policy was formulated in February 2005, whereby CQ was replaced by arthemether/lumefantrine (Coartem) as first-line drug for uncomplicated malaria, while intermittent preventive treatment (IPT) with SP was introduced to replace CQ prophylaxis in pregnancy. SP has, however, rarely been used for case management in pregnancy and, therefore, its efficacy in treating malaria in pregnant women is not known.

The aim of this study was to provide information on the efficacy of both CQ and SP in pregnant women with uncomplicated malaria. The study also aimed at providing a better understanding of the relationship between the levels of resistance found in children and in pregnant women.

\section{Methods \\ Study site}

The study was conducted between September and December 2003 at the 'Centre Médical avec Antenne Chirurgicale Paul VI' of Ouagadougou, the capital city of Burkina Faso. This health centre is situated in the north-western periurban part of the city and is the referral hospital for the corresponding health district. It comprises a maternity ward with Antenatal Care (ANC) services where pregnant women can attend at affordable costs.

Ouagadougou is located within the Sudano-Sahelian zone, with a tropical climate characterized by two seasons: a long dry season (November - May) and a rainy season lasting from June to October. In 2003, the total rainfall was $848 \mathrm{~cm}$ and the average monthly temperature ranged from $25^{\circ} \mathrm{C}$ to $33^{\circ} \mathrm{C}$ (National Meteorological Service, Ouagadougou, 2005). Malaria is endemic with a markedly seasonal transmission (July to November) $[15,16]$. Plasmodium falciparum is the most common parasite species. Until recently, CQ was used as the first-line drug for clinical malaria management and for chemoprophylaxis in pregnancy (at a weekly dose of $300 \mathrm{mg}$ ) whilst SP was the second-line drug. However, SP was rarely used in preg- nancy and not for IPT. More than $80 \%$ of pregnant women attend ANC at least once (general population census, 1995). Bed nets are not commonly used by pregnant women (Wedraogo et al, unpublished). The prevalence of HIV infection among adults in 2003 was 4.2\% (95\% CI: $2.7 \%-6.5 \%$ ) (UNAIDS, 2004). In 2002, a sentinel site surveillance found an HIV infection rate of $4 \%$ among pregnant women [17].

\section{Study protocol}

The study was conducted as a clinical efficacy trial following the protocol proposed by the WHO for monitoring antimalarial drug resistance (WHO/CDS/CSR/EPH/ 2002.17- WHO/CDS/RBM/2002.39) [18]. A 28-day follow-up design was used. The main outcomes assessed were treatment efficacy and impact on haemoglobin levels.

The inclusion criteria were as follows:

- Primigravidae or secundigravidae with gestational age between 12 and 36 weeks (fundal height less than $30 \mathrm{~cm}$ );

- Axillary temperature $\geq 37.5^{\circ} \mathrm{C}$, recent history of fever (within the 48 hours preceding enrolment) or presence of clinical malaria-related symptoms ;

- mono-infection with P. falciparum with a density $\geq 2000$ parasites $/ \mathrm{mm}^{3}$ of blood;

- Absence of clinical sign of severe malaria [19];

- Absence of other patent infections;

- Absence of previous severe reaction to CQ or SP;

- Staying in a neighbouring district or village;

- Able to come for follow-up.

- Consent

The exclusion criteria were the following:

- Clinical signs of severe malaria [19];

- Other febrile disease than malaria;

- Use of interfering treatment during the follow-up period;

- High-risk pregnancy.

Thick blood smears were prepared at Days 0, 2, 3, 7, 14, 21 and 28. Blood collection on filter papers was also done at the time of making the slides. Haemoglobin ( $\mathrm{Hb})$ 
measurement was done on days D0, D14 and D28. Axillary body temperature, at inclusion and at each follow up visit, was measured using an electronic thermometer.

The interpretation and classification of treatment outcome was performed according to the WHO protocol for low to moderate transmission areas [18]. The classification was as follows: adequate clinical and parasitological response (ACPR), early treatment failure (ETF), late clinical failure (LCF) or late parasitological failure (LPF). In cases of treatment failures occurring on D14, D21 or D28, merozoite surface protein 1 and 2 ( $m s p 1$ and $m s p 2)$ PCR genotyping was used to distinguish recrudescent parasitaemia from re-infection [20].

\section{Patient recruitment, treatment and follow up}

Primigravidae and secundigravidae attending the outpatient department (OPD) or the ANC services and fulfilling the inclusion criteria were screened for malaria parasites. Those with a positive blood slide were invited to participate in the trial. Oral informed consent was obtained from subjects before inclusion. Personal demographic information, medical and obstetrical history and a detailed history of the current illness were recorded, and a clinical and obstetrical examination performed. Gestational age was estimated by eliciting information on the date of the woman's ultimate menstrual period combined with the fundal height.

The women were randomly assigned to CQ or SP using a computer generated random number list. The study participants were seen daily for the following 3 days for control of temperature, clinical history, clinical examination, and for those assigned to the CQ group, treatment. Thereafter, they were seen on days 7, 14, 21, 28 for evaluation. SP and CQ were procured from UNICEF, Copenhagen. CQ tablets (100 mg) were administered over 3 days as: 10 $\mathrm{mg} / \mathrm{kg} /$ day on days 0 and 1 , and $5 \mathrm{mg} / \mathrm{kg} /$ day on day 2 . SP tablets were administered as a single dose of $25 \mathrm{mg}$ sulphadoxine $/ \mathrm{kg}+1.25 \mathrm{mg}$ pyrimethamine $/ \mathrm{kg}$. In practice, a quarter of tablet was given per $5 \mathrm{~kg}$ body weight. Treatment administration was directly observed, and patients were observed for the subsequent thirty minutes. In case of treatment failure, oral quinine ( $25 \mathrm{mg} / \mathrm{kg}$ bodyweight/ day in 3 doses) over five days was given as treatment. Women who had already attended ANC and who were supposed to be under CQ chemoprophylaxis were asked to stop chemoprophylaxis but to continue with iron and folic acid supplementation.

Women were invited to present as soon as possible to the research team if any complication arose during the followup period. At each follow up visit, a clinical history was taken, women were clinically examined if necessary, temperature was measured and blood obtained by finger prick. The ones who did not return for scheduled follow up visits at the clinic were visited at home. All information on clinical history, clinical examination, parasitological and haematological examinations were recorded in predesigned and tested forms and continuously updated.

\section{Laboratory methods}

Finger prick blood was used to prepare thick and thin blood films (D0 and follow up days), for Hb measurement (D0, D14 and D28), and for blood spot sampling on filter paper (Whatmann $3 \mathrm{MM}$ chromatography filter paper cut into strips of $0.5 \times 3 \mathrm{~cm}$ ) for PCR (D0 and follow up days). The thick films were air-dried, stained with Giemsa, and read using an oil immersion lens at $100 \times$ magnification. Asexual parasites were counted against 200 leucocytes and the parasite density per $\mathrm{mm}^{3}$ of blood was estimated assuming a value of 8,000 leucocytes $/ \mathrm{mm}^{3}$ of blood. At least 100 thick film fields were examined before a slide was considered negative. The parasite species were determined on the thin film. All slides were examined by two different microscopists. When the readings differed, the slide was read by a third microscopist, whose results were retained as definitive.

Haemoglobin levels were measured using a portable battery powered photometer (HemoCue $e^{\circledast B}$, Ängelholm, Sweden). Anaemia was defined as $\mathrm{Hb}<11 \mathrm{~g} / \mathrm{dL}$. An $\mathrm{Hb}$ level between 8 and $11 \mathrm{~g} / \mathrm{dL}$ was considered mild to moderate anaemia and an $\mathrm{Hb}$ level $\leq 8 \mathrm{~g} / \mathrm{dL}$ as severe anaemia.

Polymerase Chain Reaction (PCR) assays were performed on blood collected on filter papers. Genotyping for merozoite surface protein 1 and 2 ( $m s p 1$ and $m s p 2$ ) genes was performed to distinguish recrudescence of the original parasite strains from reinfection with new parasite strains as described by Snounou \& Beck [20]. Parasite DNA was extracted with methanol. The polymorphic regions of $m s p-1$, and $m s p-2$, were amplified by nested PCR [21]. Nested PCR products were analyzed by electrophoresis using $1.5 \%$ agarose gel. Genotype patterns were compared for each allele between parasites of D0 and DR (parasite recrudescence day). An outcome was defined as recrudescence if the DR sample contained identical alleles or a subset of the alleles present in the Do sample and as reinfection if the DR sample contained alleles not present in the Do infection.

\section{Statistical analysis}

The data from the case record forms were double entered using Epi- info 6.04 fr (CDC, Atlanta, USA). Data were analysed using Epi-info and SPSS 13. Continuous normally distributed data were described by the mean, standard deviation, and non-normally distributed data by the median or geometrical mean and range. Data from women lost to follow up were excluded from analysis. 
Proportions were compared using the Chi square test and normally distributed continuous variables were compared using Student's t test.

\section{Ethical considerations}

The study was approved by the National Ethical Review Committee in Burkina Faso, authorized by the Ministry of Health and recommended by the Danish National Committee on Biomedical Research Ethics. An oral informed consent was obtained from all the women before participation in the study.

\section{Results}

General characteristics of pregnant women recruited for the trial

Among 943 primigravidae and secundigravidae who consulted ANC or OPD between September $21^{\text {st }}$ and December $8^{\text {th }} 2003,255$ were in the second or third trimester of pregnancy and presented with symptoms and signs leading to a presumptive diagnosis of acute and uncomplicated malaria and were screened for malaria infection. One hundred and two women were excluded as they were either aparasitaemic or had parasitaemia $<2000$ parasites/ $\mu \mathrm{L}$ whilst one was infected with $P$. malariae. A total of 147 women (68\% primigravidae and 32\% secundigravidae) fulfilling all inclusion criteria were finally recruited (Figure 1). Median age was 20 years (range 15 to 29 years). Based on fundal height measurements, 107 (72.8\%) of the women were categorized as being in the second trimester of pregnancy, and $40(27.2 \%)$ in the third trimester. Ninety four $(63.9 \%)$ of them had not attended ANC during their pregnancy. Seventy-seven (52.4\%) had no formal education, most being housewives $(79.6 \%)$ without any income generation of their own. Ninety-nine $(81 \%)$ of the women lived in less developed areas of the district. Seventy three (49.7\%) women said they owned a bed net.

The reasons for consulting the OPD were mainly: a recent history of fever $(55.1 \%)$, fever on the day of presentation $(21.8 \%)$ and unspecific symptoms $(21.1 \%)$. These included: headache, fatigue, muscle aches and general body pains. Forty women presented with fever (axillary temperature $>=37.5^{\circ} \mathrm{C}$ ) with a mean temperature of $37.9^{\circ} \mathrm{C}(\mathrm{SD} \pm 0.4)$. Mean Parasitaemia at recruitment was 7768 asexual parasites $/ \mathrm{mm}^{3}$ [range 6353-9498] and mean $\mathrm{Hb}$ was $9.4 \mathrm{~g} / \mathrm{dl}(\mathrm{SD} \pm 1.5)$.

Seventy three $(49.7 \%)$ and $74(50.3 \%)$ were assigned to the CQ and the SP group, respectively. Among them, 16 (13.1\%) had sought care at a health centre more than a month before recruitment. Presumptive malaria had been diagnosed in nine cases. Five had been treated with CQ and four had been treated with oral quinine.

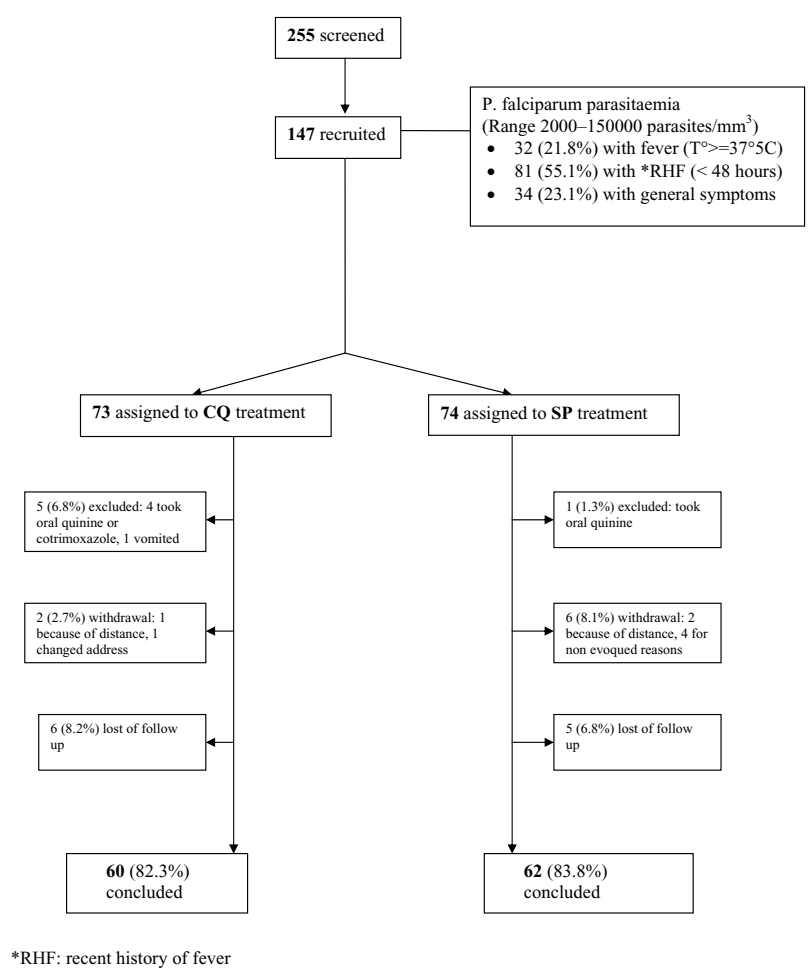

Figure I

Trial profile. (*RHF: recent history of fever)

Among the 147 enrolled women, six were excluded because they had taken other drugs during the follow-up period, eight withdrew from the study for various reasons and 11 were lost to follow up. One hundred and twenty two completed the study with 60 in the CQ group and 62 in the SP group, respectively (Figure 1). Baseline characteristics of the women who completed the 28-day followup are summarized in Table 1. No adverse reaction attributable to treatment were reported to the research team neither those who completed the follow up or nor from those who withdrew by themselves.

\section{Parasiteamia and gametocyteamia}

At inclusion, parasiteamia ranged from 2000 to 150000 parasites $/ \mathrm{mm}^{3}$ with a median of 6000 parasites $/ \mathrm{mm}^{3}$. Only two patients had a parasiteamia $\geq 100,000$ parasites/ $\mathrm{mm}^{3}$. There was no significant difference in mean parasiteamia between primigravidae (7922 [5941-10564]) and secundigravidae (7768 [5302-11380]) $P=0.937$. The prevalence of gametocytes on the day of recruitment was $4 \%$. It remained around $4 \%$ in the two treatment groups apart from D7 where an increase was observed in both CQ group (6.7\%) and SP group (17.7\%) and among the CQ group at D28 (8.8\%). No gametocytes were observed at D28 among the eight women in the SP group with LPF. 
Table I: Baseline characteristics of pregnant women with uncomplicated malaria who completed the 28 days therapeutic efficacy assessment in Ouagadougou, 2003.

\begin{tabular}{|c|c|c|c|}
\hline \multirow[t]{2}{*}{ Baseline characteristics } & \multirow[t]{2}{*}{ Total $(n=122)$} & \multicolumn{2}{|c|}{ Treatment group } \\
\hline & & $C Q(n=60)$ & $S P(n=62)$ \\
\hline Median age in years [range] & $20[15-29]$ & $20[15-28]$ & $19.5[15-29]$ \\
\hline Primigravidae & $83(68 \%)$ & $41(68.3 \%)$ & $42(67.7 \%)$ \\
\hline Secundigravidae & $39(32 \%)$ & $19(31.7 \%)$ & $20(32.3 \%)$ \\
\hline Presented with fever & $28(22.9 \%)$ & $19(31.7 \%)$ & $9(14.5 \%)$ \\
\hline Temperature (mean) & $37.9( \pm 0.5)$ & $38( \pm 0.5)$ & $37.8( \pm 0.3)$ \\
\hline $\begin{array}{l}\text { Parasite count (geometric mean/ } \\
\left.\mathrm{mm}^{3}\right) \text { [range] }\end{array}$ & 7874 [6269-9889] & $8055[5840-111111]$ & $7699[5523-10732]$ \\
\hline Haemoglobin D0 (g/dL) & $9.4( \pm 1.6)$ & $9.5( \pm 1.6)$ & $9.3( \pm 1.6)$ \\
\hline \multicolumn{4}{|l|}{ Anaemia: } \\
\hline - severe $(\mathrm{Hb}<8 \mathrm{~g} / \mathrm{dL})$ & $23(18.8 \%)$ & $12(20 \%)$ & $14(22.6 \%)$ \\
\hline $\begin{array}{l}\text { - mild to moderate }(\mathrm{Hb} 8-<11 \\
\mathrm{g} / \mathrm{dL})\end{array}$ & $73(59.9 \%)$ & $38(63.3 \%)$ & $35(56.4 \%)$ \\
\hline - Absence $(\mathrm{II}+\mathrm{g} / \mathrm{dL})$ & $26(21.3 \%)$ & $10(16.7 \%)$ & 13 (21\%) \\
\hline
\end{tabular}

Gametocytes were associated with recrudescence of asexual parasites in $19.4 \%$ of the failures.

\section{Anaemia}

The prevalence of anaemia among the women was $81 \%$ (21\% with severe anaemia and $60 \%$ with mild to moderate anaemia). At admission there was no significant difference in mean $\mathrm{Hb}$ between primigravidae $(9.3 \mathrm{~g} / \mathrm{dL} \pm 1.6)$ and secundigravidae $(9.5 \mathrm{~g} / \mathrm{dL} \pm 1.6, P=0.65)$. Curiously, mean $\mathrm{Hb}$, at inclusion, was higher in women who had not previously attended ANC $(9.6 \mathrm{~g} / \mathrm{dL} \pm 1.6)$ compared with those who had attended at least once $(9.0 \mathrm{~g} / \mathrm{dL} \pm 1.4, P=$ 0.04 ) and who were supposed to have received chemoprophylaxis with CQ and iron/folic acid supplementation.

In patients successfully treated with $C Q$, no significant gain on $\mathrm{Hb}$ level was evident at D14 $(P=0.49)$ nor at D28 $(P=0.34)$ as compared to D0. On the other hand, patients treated with SP gained $0.38 \mathrm{~g} / \mathrm{dL}$ at D14 $(P=0.006)$ and $0.9 \mathrm{~g} / \mathrm{dL}$ at D28 $\left(\mathrm{p}<10^{-3}\right)$. Although mean Hb levels were found to be lower at D14 or D28 among treatment failures, the reduction was not significant.

\section{Therapeutic efficacy}

The PCR corrected results on therapeutic efficacy at day 14 and day 28 are presented in Table 2. One case of LPF in the CQ group was reclassified as a re-infection by PCR. Almost half of the women $(28,46.7 \%)$ treated with CQ were not cured of their infection. Most demonstrated LPF. In the SP group failure (all LPF) occurred in $12.9 \%$.

There were as many treatment failures in primigravidae as in secundigravidae with CQ $(43.9 \%$ and $47.4 \%$, respectively $(P=0.8))$ and SP $(14.2 \%$ and $10 \%$, respectively $(P$
$=0.6)$ ). Failures rates were also similar irrespective of the trimester of pregnancy $(P=0.77)$. The frequency of treatment failures was not different between women who had attended ANC at least once (30.4\%) and those who had no prior attendance to ANC $(27.3 \%, P=0.74)$.

Treatment failures were found in three of the nine women who had reported a recent illness episode diagnosed as presumptive malaria. All three of them had received oral quinine for treatment. Recrudescent parasiteamia at D14 (CQ: 5, SP: 1) or at D28 (CQ: 7, SP: 6) were usually of low density, ranging from 40 to 2,000 parasites $/ \mathrm{mm}^{3}$.

According to the modified classification of parasitological response [22], $13.3 \%$ early RI, 36.6\% late RI, and $1.6 \%$ RII were found in the CQ treatment group while $1.6 \%$ early RI, 9.7\% late RI, and 3.2\% RII were found in the SP treatment group. No case of RIII response was found to any treatment group.

\section{Discussion}

In the present study the efficacy of CQ and SP was assessed in primigravidae and secundigravidae presenting with uncomplicated malaria. CQ and SP had until recently been recommended in Burkina Faso as antimalarial drugs for first and second line treatment. The study was undertaken to specifically assess the treatment efficacy among pregnant women as they may be considered a distinct subgroup of the population, with regard to malaria immunity and treatment outcomes. Usually antimalarial drug efficacy has been assessed in non-immune children less than 5 years of age, but no data are available on the correlation between antimalarial drug efficacy assessed in children under five years of age and efficacy in other segments of the population. Although antimalarial immunity is 
Table 2: CQ and SP therapeutic assessment cumulative results at day 14 and day 28 in pregnant women in Ouagadougou, 2003.

\begin{tabular}{|c|c|c|c|c|}
\hline \multirow[t]{2}{*}{ Assessment results } & \multicolumn{2}{|c|}{$C Q$ treatment group $(n=60)$} & \multicolumn{2}{|c|}{ SP treatment group $(n=62)$} \\
\hline & DI4 & D28 & DI4 & D28 \\
\hline ETF & I (I.7\%) & I (I.7\%) & $0(0 \%)$ & $0(0 \%)$ \\
\hline LCF & I (I.7\%) & $3(5 \%)$ & $0(0 \%)$ & $0(0 \%)$ \\
\hline LPF & $6(10 \%)$ & $24(40 \%)$ & $3(4.8 \%)$ & $8(12.9 \%)$ \\
\hline ACPR & $52(86.6 \%)$ & $32(53.3 \%)$ & $59(95.2 \%)$ & $54(87.1 \%)$ \\
\hline Total & $60(100 \%)$ & $60(100 \%)$ & $62(100 \%)$ & $62(100 \%)$ \\
\hline
\end{tabular}

ETF: early treatment failure

LCF: late clinical failure

LPF: late parasitological failure

ACPR: adequate clinical and parasitological response

impaired in pregnancy, especially among primigravidae, the level of immunity is considered to be higher in adult pregnant women than among under-five year olds [2325] and a high level of treatment failures among this young age group might not be reflected in pregnant women. In Burkina Faso, anti-malarial prophylaxis with $\mathrm{CQ}$ given in sub-therapeutic weekly dose regimens is available for pregnant women attending ANC. This might select for resistant strains, allow asymptomatic parasite carriage $[26,27]$ and be the explanation for anaemia and treatment failures. It is, therefore, of public health interest to assess the drugs efficacy in such a specific group. Furthermore it was recently found that CQ chemoprophylaxis was not effective [11] due to high levels of parasite resistance. In this context, it was found it useful to assess the efficacy of SP among pregnant women before introducing this drug for IPT as replacement for CQ prophylaxis.

The standardized WHO protocol for low to moderate transmission areas was adapted for use with pregnant women in whom clinical malaria doesn't always present with typical symptoms. Malarial fever may not occur in adults even in pregnant women with some degree of impaired immunity $[28,29]$. In this study, consideration was mainly given to anamnestic signs and history of fever associated with parasite carriage in order to increase the number of subjects enrolled and to take into account those women who presented without fever but who complained of malaria related symptoms in association with parasites in peripheral blood. Thus, only $21.8 \%$ of enrolled women presented with fever on the day of enrolment. Unfortunately the follow-up did not include specific inquiries about the disappearance of the symptoms present at inclusion but rather assessed the general clinical improvement which, when associated with parasite clearance, could be considered as a recovery. Safety was not specifically addressed in this study, but both SP and CQ are commonly used during pregnancy and known to be safe when administered at the recommended doses: CQ throughout the pregnancy and SP in the second and third trimester [30].

In the CQ group, ETF were observed in only $1.7 \%$ of cases while LCF were observed in $5 \%$ of cases, bringing total clinical failures to $6.7 \%$. The incidence of clinical failures was low in this study and would have been acceptable if not associated with a high incidence of LPF $(40 \%)$ which indicates that when extending follow-up beyond 14 days the level of resistance to CQ makes it unsuitable for treatment. On the other hand, no case of clinical failure, either ETF or LCF was found in the SP group, all failures being LPF $(12.9 \%)$. These findings indicates that SP has retained a reasonable level of efficacy for treatment of uncomplicated malaria in pregnancy and that it still remains a valuable drug for IPT. However, there is a serious risk that resistance to SP may develop quickly if used for general malaria case management further compounded by the widespread use of cotrimoxazole, another sulpha drug which could generate cross resistance with SP $[31,32]$.

A 28-day efficacy study was conducted in under-five year old children at the same period as the present study in a neighbouring health district of Ouagadougou [10]. Overall failure rates of $63.4 \%(87 / 137)$ to CQ and $13.8 \%$ (17/ $125)$ to SP were recorded. ETF rates were higher within the CQ group than in the SP group. These failure rates were higher than the $46.7 \%$ observed in pregnant women for CQ $(P=0.02, \mathrm{RR}=1.36 \mathrm{CI} 95 \%: 1.01-1.83)$, but similar to the $12.9 \%$ observed for SP $(P=0.89)$. Furthermore, ETF was more common in children than in pregnant women. These observations suggest that, beyond a general decrease in CQ and SP efficacy, failure rates to CQ are lower in pregnant women than in children. This is probably due to the higher level of humoral immunity in pregnant women [23]. However, efficacy rates remained comparable for SP under the same conditions. 
Contrary to CQ, SP induced a gain in mean Hb by day 14 which further increased by day 28 , indicating that malaria is an important contributing factor to anaemia in pregnancy [33]. Women attending ANC are supposed to take chemoprophylaxis and iron and folic supplementation to prevent anaemia. Testing CQ in women under chemoprophylaxis could be seen as unsuitable due to the long half life of $\mathrm{CQ}$, but no data were available regarding the compliance with the chemoprophylactic regimen. Furthermore, it was common practice at the health facilities to treat malaria attacks in pregnant women with CQ and the efficacy of CQ and SP was not found related to ANC attendance. In Burkina Faso regular attendance to ANC services is low. Most of the women included in the study came for treatment of an illness rather than for attending ANC although the visit at the OPD was used by the health centre staff to attempt to enrol the women for ANC. Complaints about side effects of CQ, especially bitterness and drowsiness are common, and although compliance was not assessed in this study, it might be very low. This could be the explanation of a lower mean $\mathrm{Hb}$ level on the day of inclusion in women who had at least visited ANC once prior to the admission visit.

\section{Conclusion}

CQ has lost its efficacy for malaria case management in pregnant women in the study area and chemoprophylaxis with this drug cannot effectively prevent malaria in pregnancy [11]. Its use in pregnancy should be replaced with alternative drugs and this was recently implemented by the Ministry of Health of Burkina Faso which changed to a policy of IPT with SP given once in the second and third trimester (Ministry of Health, February 2005). With ETF less than 15\%, SP must still be considered as being reasonably efficacious and, in the absence of alternatives, its use for case management remains possible. However, since widespread use of SP can rapidly lead to resistance [34-37] it's use for only IPT in pregnant women rather than for treatment is recommend.

\section{Authors' contributions}

SOC conceived the study and its design, he participated and coordinated the collection of data. He analysed the data and drafted the manuscript. PM helped in designing the study, interpreting the results and critically revised the manuscript. BK contributed in designing the study and revising the manuscript. DN and ST participated in coordination of data collection and data analysis. All authors read and approved the final manuscript.

\section{Acknowledgements}

We sincerely thank all the women who accepted to participate in the study despite many difficulties. We also thank the medical staff of "CMA Paul VI" ANC and OPD services for their useful help in recruitment and follow up of participants. Particular thanks to Dr. Etienne Kaboré who helped with organization and to Magloire Natama for help in carrying out the PCR reac- tions. This study was funded by the Gates Malaria Partnership and DBL Institute for Health research and development. We thank ATCC/MR4 for kindly providing the necessary PCR reagents.

\section{References}

I. World Health Organization: A Strategic Framework for Malaria Prevention and Control During Pregnancy in the African Region. Brazzaville: WHO Regional Office for Africa; 2004. AFR/ MAL/04/0I

2. Brabin BJ: An analysis of malaria in pregnancy in Africa. Bull World Health Organ 1983, 61:1005-1016.

3. Brabin $B J$ : The risks and severity of malaria in pregnant women. In Applied Field Research in Malaria reports, no I Geneva, Switzerland. World Health Organization; 199I. (TDR/FIELDMAL/I)

4. McGregor IA: Epidemiology of malaria and pregnancy. $\mathrm{Am} J$ Trop Med Hyg 1984, 33:517-525.

5. Mutabingwa TK: Malaria and pregnancy: epidemiology, pathophysiology and control options. Acta Trop 1994, 57:239-254.

6. Menendez C, Ordi J, Ismail MR, Ventura PJ, Aponte JJ, Kahigwa E, Font $\mathrm{F}$, Alonso PL: The impact of placental malaria on gestational age and birth weight. J Infect Dis 2000, I 8 I: I740-I745.

7. Nyirjesy P, Kavasya T, Axelrod P, Fischer PR: Malaria during pregnancy: neonatal morbidity and mortality and the efficacy of chloroquine chemoprophylaxis. Clin Inf Dis 1993, 16:127-132.

8. Guyatt HL, Snow RW: The epidemiology and burden of Plasmodium falciparum -related anemia among pregnant women in sub-Saharan Africa. Am J Trop Med Hyg 200I, 64(I-2 Suppl):36-44.

9. ter Kuile FO, Parise ME, Verhoeff FH, Udhayakumar V, Newman RD, van Eijk AM: The burden of co-infection with human immunodeficiency virus type $I$ and malaria in pregnant women in sub-saharan Africa. Am J Trop Med Hyg 2004, 7 I (2 Suppl):4 I-54.

10. Gansané A, Nebié I, Diarra A, Ouédraogo A, Soulama I, Bougouma E, Tiono A, Dermé A, Konaté A, Sirima B: Efficacy of chloroquine and sulfadoxine-pyrimethamine for the treatment of uncomplicated malaria in Ouagadougou, capital city of Burkina Faso. Acta Trop 2005, 95S:SI-S506. [MIM-GA-278I03]

II. Sirima SB, Tiono AB, Konate A, Diarra A, Castelli F, Pinoges L, Mugittu K, Taylor WR, Olliaro PL: Efficacy of artesunate plus chloroquine for the treatment of uncomplicated malaria in children in Burkina Faso: a double-blind, randomized, controlled trial. Trans R Soc Trop Med Hyg 2003, 97:345-349.

12. Tinto $H$, Zoungrana EB, Coulibaly SO, Ouedraogo JB, Traore $M$ Guiguemdé TR, Van Marck E, D'Alessandro U: Chloroquine and sulphadoxine-pyrimethamine efficacy for uncomplicated malaria treatment and haematological recovery in children in Bobo-Dioulasso, Burkina Faso during a 3-year period 1998-2000. Trop Med Int Health 2002, 7:925-930.

13. Coulibaly SO: Chloroquine and sulfadoxine-pyrimethamine efficacy monitoring in Burkina Faso: results of 3 years studies using WHO I 4 days protocol. [abstract]. In Moving Targets: Parasites, Resistance and Access to Drugs; International Colloquium, Antwerp, 4-6 December, 2000. Abstract book Prince Leopold Institute of Tropical Medicine, Antwerp, Belgium; 2000:39.

14. Guiguemdé TR, Aouba A, Ouedraogo JB, Lamizana L: Ten-year surveillance of drug resistant malaria in Burkina Faso (1982I 99 I). Am J Trop Med Hyg 1994, 50:699-704.

15. Rossi P, Belli A, Mancini L, Sabatinelli G: A longitudinal entomologic survey on the transmission of malaria in Ouagadougou (Burkina Faso). Parassitologia 1986, 28: I-I5.

16. Sabatinelli G, Bosman A, Lamizana L, Rossi P: Prevalence of malaria in Ouagadougou and the surrounding rural environment during the period of maximal transmission. Parassitologia 1986, 28:|7-3|.

17. Burkina Faso, Ministère de la Santé, Direction des études et de la planification: Annuaire statistique 2004. 2005.

18. World Health Organization: Monitoring Antimalarial drug resistance. Report of a WHO consultation. In WHO/CDS/CSR/ EPH/2002.I 7- WHO/CDS/RBM/2002.39 World Health Organization, Geneva, Switzerland; 200 I.

19. World Health Organization: Severe falciparum malaria. Trans $R$ Soc Trop Med Hyg 2000, 94(supplement I):

20. Snounou G, Beck H: The use of PCR genotyping in the assessment of recrudescence or reinfection after antimalarial drug treatment. Parasitol Today 1998, 14:462-467. 
21. Ranford-Cartwright LC, Taylor J, Umasunthar T, Taylor LH, Babiker HA, Lell B, Schmidt-Ott JR, Lehman LG, Walliker D, Kremsner PG: Molecular analysis of recrudescent parasites in a Plasmodium falciparum drug efficacy trial in Gabon. Trans $R$ Soc Trop Med Hyg 1997, 91:719-724.

22. Ringwald P, Basco LK: Comparison of in vivo and in vitro tests of resistance in patients treated with chloroquine in Yaoundé, Cameroon. Bull World Health Organ 1999, 77:34-43.

23. Weinberg ED: Pregnancy-associated depression of cell-mediated immunity. Rev Infect Dis 1984, 6:8|4-83।.

24. Hunt JS: Immunobiology of pregnancy. Curr Opin Immunobiol 1992, 4:59|-596.

25. Fievet N, Cot M, Chougnet C, Maubert B, Bickii J, Dubois B, Le Hes$\operatorname{ran} J \mathrm{Y}$, Frobert $\mathrm{Y}$, Migot $\mathrm{F}$, Romain $\mathrm{F}$ : Malaria and pregnancy in Cameroonian primigravidae: humoral and cellular immune responses to Plasmodium falciparum blood-stage antigens. Am J Trop Med Hyg 1995, 53:6 12-6I7.

26. Mockenhaupt FP, Rong B, Till H, Eggelte TA, Beck S, Gyasi-Sarpong C, Thompson WN, Bienzle U: Submicroscopic Plasmodium falciparum infections in pregnancy in Ghana. Trop Med Int Health 2000, 5:167-73.

27. Mockenhaupt FP, Ulmen U, von Gaertner C, Bedu-Addo G, Bienzle U: Diagnosis of placental malaria. J Clin Microbiol 2002, 40:306-308.

28. Gomes M, Espino FE, Abaquin J, Realon C, Salazar NP: Symptomatic identification of malaria in the home and in the primary health care clinic. Bull World Health Organ 1994, 72:383-390.

29. Genton B, Smith T, Baea K, Narara A, al-Yaman F, Beck HP, Hii J, Alpers M: Malaria: how useful are clinical criteria for improving the diagnosis in a highly endemic area? Trans $R$ Soc Trop Med Hyg 1994, 88:537-54I

30. Phillips-Howard PA, Wood D: The safety of antimalarial drugs in pregnancy. Drug Safety 1996, 14:131-145.

31. Petersen E: In vitro susceptibility of Plasmodium falciparum malaria to pyrimethamine, sulfadoxine, trimethoprim and sulfamethoxazole, singly and in combination. Trans $R$ Soc Trop Med Hyg 1987, 8:238-24l.

32. Triglia T, Menting JG, Wilson C, Cowman AF: Mutations in dihydropteroate synthase are responsible for sulfone and sulfonamide resistance in Plasmodium falciparum. Proc Natl Acad Sci USA 1997, 94: 13944-13949.

33. Ndyomugyenyi R, Magnussen P: Anaemia in pregnancy: Plasmodium falciparum infection is an important cause in primigravidae in Hoima district, western Uganda. Ann Trop Med Parasitol 1999, 93:457-465.

34. Marks F, von Kalckreuth V, Kobbe R, Adjei S, Adjei O, Horstmann RD, Meyer CG, May J: Parasitological rebound effect and emergence of pyrimethamine resistance in Plasmodium falciparum after single-dose sulfadoxine-pyrimethamine. J Infect Dis 2005, 192: 1962-1965.

35. Terlouw DJ, Nahlen BL, Courval JM, Kariuki SK, Rosenberg OS, Oloo AJ, Kolczak MS, Hawley WA, Lal AA, Kuile FO: Sulfadoxinepyrimethamine in treatment of malaria in Western Kenya increasing resistance and underdosing. Antimicrob Agents Chemother 2003, 47:2929-2932.

36. Talisuna AO, Bloland P, D'Alessandro U: History, dynamics, and public health importance of malaria parasite resistance. Clin Microbiol Rev 2004, 17:235-254.

37. Mugittu K, Abdulla S, Falk N, Masanja H, Felger I, Mshinda H, Beck HP, Genton B: Efficacy of sulfadoxine-pyrimethamine in Tanzania after two years as first-line drug for uncomplicated malaria: assessment protocol and implication for treatment policy strategies. Malar J 2005, 4:55.
Publish with Bio Med Central and every scientist can read your work free of charge

"BioMed Central will be the most significant development for disseminating the results of biomedical research in our lifetime. "

Sir Paul Nurse, Cancer Research UK

Your research papers will be:

- available free of charge to the entire biomedical community

- peer reviewed and published immediately upon acceptance

- cited in PubMed and archived on PubMed Central

- yours - you keep the copyright

Submit your manuscript here:

http://www.biomedcentral.com/info/publishing_adv.asp
BioMedcentral 